\title{
Characterization of IN 625 recycled metal powder used for selective laser melting
}

\author{
Mihaela Raluca Condruz , Gheorghe Matache, and Alexandru Paraschiv \\ Romanian Research \& Development Institute for Gas Turbines - COMOTI, 220 D Iuliu Maniu Av., Bucharest, Romania
}

Received: 21 November 2019 / Accepted: 8 January 2020

\begin{abstract}
Additive manufacturing of high-quality materials by Selective Laser Melting depends not only on establishing appropriate process parameters, but also on the characteristics of the metal powders used and their stability over time or after recycling. The aim of the research was to characterize the IN 625 powder used over multiple manufacturing cycles with a Lasertec 30 SLM machine. In order to achieve the research's goal, virgin and recirculated powder's physical and technological characteristics were investigated. A decrease in all Dvalues $\left(\mathrm{D}_{10}, \mathrm{D}_{50}, \mathrm{D}_{90}\right)$ of the powder size distribution was observed after multiple recirculation cycles showing a decrease of the powder dimensional range over time. Both virgin and recirculated powders are composed of mainly spherical particles, but elongated particles and satellite particles were observed as well. The dimensional evolution analysis showed a deviation from the powder ideal roundness, deviation that is more pronounced over multiple recirculation cycles. It was experimentally determined that the powders present a good flowability based on the flow rate value obtained for both virgin and recirculated powders, confirmed also by the Hausner ratio and angle of repose.
\end{abstract}

Keywords: IN 625 / SLM / recycling / metallic powder / additive manufacturing

\section{Introduction}

Nowadays the global economy is demanding innovative and customized products with improved properties which should be manufactured by "green" or sustainable technologies. Thereby, many industrial sectors, government agencies and academic centers are focusing their researches on alternative manufacturing technologies such as additive manufacturing (AM). Even if it is commercially available since late 1980s, many AM methods were developed ever since, there are still unknown technological aspects that restrain the use of this technology on parts mass production. In case of metallic parts manufacturing, two methods are the most studied, Selective Laser Melting (SLM) and Electron Beam Melting (EBM).

Most of the available published papers are focused on proper process parameters establishment, mechanical properties evaluation of the produced materials, microstructure and defect evaluation, while a limited number of studies were found regarding the powder stability over time and after recycling, even if the feedstock characteristics affect both AM process and the quality of the final product. $^{1}$

\footnotetext{
* e-mail: raluca.condruz@comoti.ro

${ }^{1}$ https://equispheres.com/cold-spray/\#am
}

Metallic powders should exhibit particular characteristics in order to be appropriate for AM processes. Usually, the AM machine vendors suggest that smooth spherical particles are the most suited in order to obtain high density parts, and the existing literature sustains their claim. Three methods are most used for the production of metallic powders used with AM: gas atomization (GA), plasma atomization (PA) and plasma rotating electrode process (PREP). Depending on the processing conditions, different other powder morphologies can be obtained (like irregular, satellite, "splat cap", elongated, broken, agglomerated etc.) [1-6]. Smooth spherical powders are the most desired for AM processes because they ensure a better flowability compared to other morphologies, a higher flow rate is achieved by a reduced inter-particular friction and low risk of mechanical interlocking [6]. ${ }^{2}$

Another important aspect that affects the characteristics of AM parts is the particle size distribution (PSD). Different opinions were encountered in the literature regarding the optimum PSD. Some researchers stated that mono-sized powders (narrow size distribution) can improve the repeatability of the AM process and provide superior and consistent mechanical properties to the final product, while other researchers state that higher densities

\footnotetext{
$\overline{2}$ https://www.freemantech.co.uk/_powders/powder-flowabilitymechanisms-of-particle-interaction
} 
are obtained using multimodal powder distributions (Furnas model) $[2,7,8]$. Smaller particles can be distributed between large particles, reducing the pores and ensuring a higher compaction degree. Nguyen et al. [1] claim that for SLM, the optimum powders should have a PSD in the range of $15-63 \mu \mathrm{m}$, observation sustained by other studies [6]. Spierings et al. [9] shows that PSD influences the density of developed parts.

Companies tend to use virgin powders for AM in order to maintain consistency of parts properties. However, few powder recycling techniques are used in practice, even if they are not completely qualified. For example, virgin powders are blend with recycled powders before starting a new job in order to reduce the oxygen content or they are recycled by sieving to remove any oversized or overexposed particles. Another technique is the induction plasma process consisting of in-flight heating and melting of feedstock followed by solidification under controlled conditions [10,11].

It was experimentally determined that recycling the powder by sieving before a job has a negligible influence on the chemical composition of powders, on the shape or on the PSD. In some cases, some modifications of the tensile properties after recycling were observed, but in other cases even if changes in rheological properties of powder were encountered, they did not affect the mechanical properties. It was found that recycling processes affect the technological characteristics of powders (apparent density, tapped density, flowability) [11-15].

The goal of the current work was to characterize the evolution of IN 625 powders used over multiple AM processes in order to obtain parts with Lasertec 30 SLM machine.

\section{Experimental procedure}

\subsection{Materials and procedures}

For this study IN 625 metal powder supplied by LPW Technology Ltd. (subsidiary of Carpenter Technology Corporation) was used (batch UK 81572). The metal powder was manufactured by vacuum melting followed by gas atomization and sorted within a particle size range of 15$45 \mu \mathrm{m}$. The AM equipment used was a Lasertec 30 SLM machine manufactured by DMG MORI. In order to achieve the research's goal, virgin powder was extracted from a sealed powder container and recirculated powder was collected from the machine tank (the samples were extracted after finishing a job). Powder samples were randomly extracted from different places of the sealed container and from the machine building area, using a spatula (Fig. 1).

Lasertec 30SLM has embedded a powder recycling system which involves the powder recirculation over multiple manufacturing cycles. After finishing every job, the powder is extracted from the machine building area with a vacuum cleaner and automatically transferred in the powder car. A rotary feeder dispenses the metal powder into a cyclone separator that transfers the powder to an ultrasonic sieving unit which ensures the powder sieving and prevents nonconforming powders to be reused (powders sizes over $70 \mu \mathrm{m}$ ). After the sieving process is finished, the nonconforming powder is transferred to an

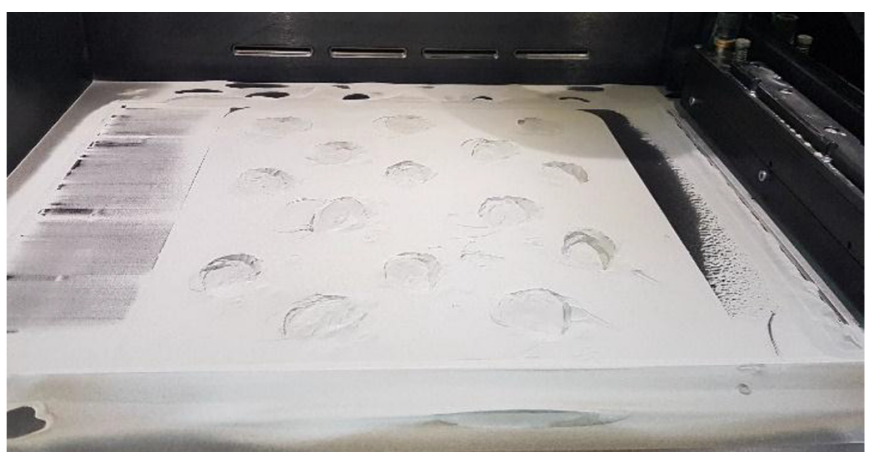

Fig. 1. Random sampling of recirculated powder after a manufacturing cycle from the machine building area.

overflow vessel of the sieving unit (to collect big powder particles that does not pass through the sieving mesh) and the congruent powder is send to the main powder tank.

Some important powder physical and technological characteristics were investigated: PSD, morphology and surface quality, apparent and tapped density, flowability.

The PSD was assessed by sieving analysis, using a vibratory sieve shaker Retsch AS 200 control equipped with standardized woven wire mesh sieve set (ISO 3310-1 [16], sieves dimensions $(\mathrm{D} \times \mathrm{H}) 100 \times 40 \mathrm{~mm}$, mesh sizes: $20 \mu \mathrm{m}, 25 \mu \mathrm{m}, 32 \mu \mathrm{m}, 36 \mu \mathrm{m}, 40 \mu \mathrm{m}, 45 \mu \mathrm{m}, 50 \mu \mathrm{m}$, along with a pan and a cap). The sieving analysis was performed according to the requirements of DIN 66165-1 [17], DIN 66165-2 [18] and ASTM B214-16 [19] standards.

The following parameters were used:

- total powder quantity used for a PSD determination: $200 \mathrm{~g}$;

- weight of a sample: $50 \mathrm{~g}$ (a PSD was determined based an average made on 4 samples);

- sieving duration: 5 min;

- amplitude: $2 \mathrm{~mm}$;

- interval time: $60 \mathrm{~s}$;

- no sieving aids were used;

- no sample preparation was performed.

The evolution of powder PSD was determined based on sieving analysis performed on the samples described in Table 1.

The manufacturing trials were started with $50 \mathrm{~kg}$ of virgin powder in the machine tank and over a period of 6 months, $90 \mathrm{~kg}$ of virgin powder was added in the tank at different periods of time. Taking into account the weight of the powder filled in the machine tank, the parts manufactured and the incongruent powder removed from the overflow vessel, it was estimated that the powder was recirculated eight times over the whole period.

The morphology and surface quality analysis of the powder particles were investigated by SEM according to ISO/ASTM DIS 52907 [20]. Based on SEM images, a dimensional evolution of powders was also assessed. Using the software Scandium, different measurements were realized on 50 powder particles from 3 different SEM images (taken at $1000 \times$ magnification), for each type of powder (virgin or recirculated). This evolution was determined based on parameters encountered in the 
Table 1. Powder samples used for PSD determination.

\begin{tabular}{llll}
\hline No. & Powder type & Code & Observations \\
\hline 1 & Virgin powder & V & - \\
2 & $\begin{array}{l}\text { Recirculated } \\
\text { powder }\end{array}$ & R1 & Sampled after 4 manufacturing cycles \\
3 & & R2 & Sampled after 19 manufacturing cycles (including the previous 4 manufacturing cycles) \\
4 & & R3 & Sampled after 28 manufacturing cycles (including the previous 19 manufacturing cycles) \\
5 & & R4 & Sampled after 37 manufacturing cycles (including the previous 28 manufacturing cycles) \\
\hline
\end{tabular}

literature, like particle's elongation and particle's roundness [21]. In order to obtain an accurate dimensional evolution, different shaped powders were taken into account (round particles, particles with satellites, elongated particles) as well as different size particles (smaller or larger particles) which were completely visible in the SEM images.

The elongation is a sign of the anisometry degree of particles and is determined by dividing the greatest length $(L)$ at the greatest width $(B)$ of a particle. Particle's elongation was determined using equation (1), while particle's roundness was determined using two equations, Wentworth's equation (2) and Cailleux's equation (3). For elongation measurements the Feret's diameter was considered, representing the distance between two tangents on opposite sides of the particle being evaluated [21].

$$
E=\frac{L}{B}
$$

$$
\begin{aligned}
R_{W} & =\frac{\text { radius of curvature of the most convex part }}{\frac{L+B}{4}} \\
R_{C} & =\frac{\text { radius of curvature of the most convex part }}{\frac{L}{2}}
\end{aligned}
$$

where $E$ - elongation of the particle; $L-$ the greatest length of the particle; $B$ - the greatest width at rightangles; $R_{W}-$ Wentworth's roundness; $R_{C}-$ Cailleux's roundness.

Figure 2 presents suggestive images used to measure $L$, $B$ and the diameter of the most convex part which was afterwards used to calculate the radius of curvature.

Apparent density of powder was determined according to ISO 3923-1 [22], while tapped density was determined according to ISO 3953 [23]. For apparent density, $25 \mathrm{~cm}^{3}$ of virgin and recirculated powder were passed by a Carney Funnel with a $5 \mathrm{~mm}$ diameter in a $25 \mathrm{~cm}^{3}$ cylinder, the powder excess being carefully wiped with a metallic scraper. The quantity of powder retained in the $25 \mathrm{~cm}^{3}$ cylinder was weighted and the apparent density was calculated by dividing the weight by the volume. Tapped density was measured by repeating the same actions as in case of the apparent density determination with the difference that the powder was put afterwards in a measuring cylinder and it was manually tapped for 200 times. The volume of the tapped powder was directly read on the scale of the cylinder and the tapped density was calculated by dividing the weight by the tapped powder volume. Three measurements were made for each powder type and average values were calculated.

The powder flowability was assessed based on the Hausner ratio (HR), Carr index (C), powder repose angle (AOR) and flow rate according to ASTM B964 [24] using a Carney Funnel.

Hausner ratio was determined using equation (4), while Carr index was determined using equation (5).

$$
\begin{gathered}
H R=\frac{\rho_{t}}{\rho_{a}} \\
C=100 \frac{\rho_{t}-\rho_{a}}{\rho_{t}}
\end{gathered}
$$

where $\rho_{t}$ - powder tapped density $\left(\mathrm{g} / \mathrm{cm}^{3}\right) ; \rho_{\mathrm{a}}-$ powder apparent density $\left(\mathrm{g} / \mathrm{cm}^{3}\right)$.

Hausner ratio is correlated to the flowability of a powder, while Carr index indicates the compressibility of a powder, and the relation between them can be defined as:

$$
H R=\frac{100}{(100-C)}
$$

Usually, a powder which presents a Hausner ratio higher than 1.25 is characterized by a poor flowability, while powders with Carr index higher than 16 are characterized by a poor compressibility. The Carr index is more relevant to conventional powder metallurgy methods rather than to AM technology.

The AOR measures the angular difference between the slope of the accumulated powder heap and the base plate where a low angle or shorter discharge period depicts better flowability. There are no public standards governing the angle of repose measurement for metal alloy powders and usually the results obtained are only used as a comparison against powder's historic performance and previous powder batches to confirm consistency of performance [25]. For this type of measurements an in-house device was used (Fig. 3). The device consists of an empty metallic 


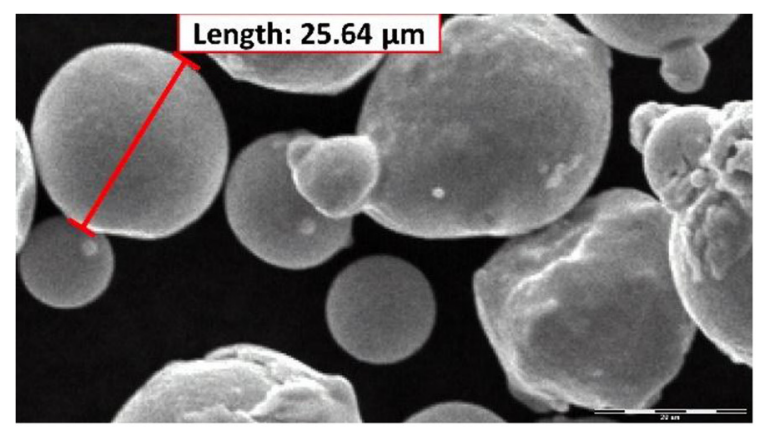

a)

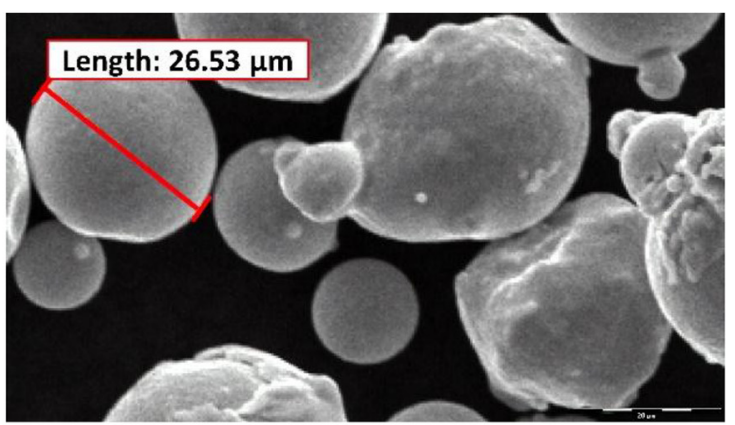

b)

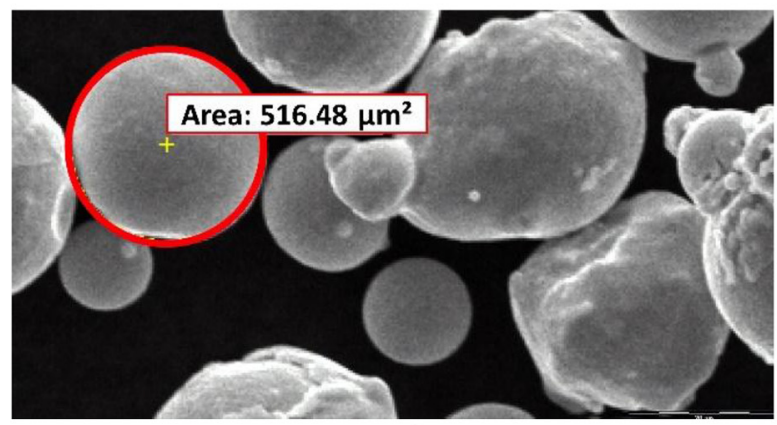

c)

Fig. 2. Representative processed images used for powder particle's dimensional evolution analysis. (a) Measurement of B parameter. (b) Measurement of L parameter. (c) Measurement of the diameter of the most convex part of a particle which was used for radius determination.
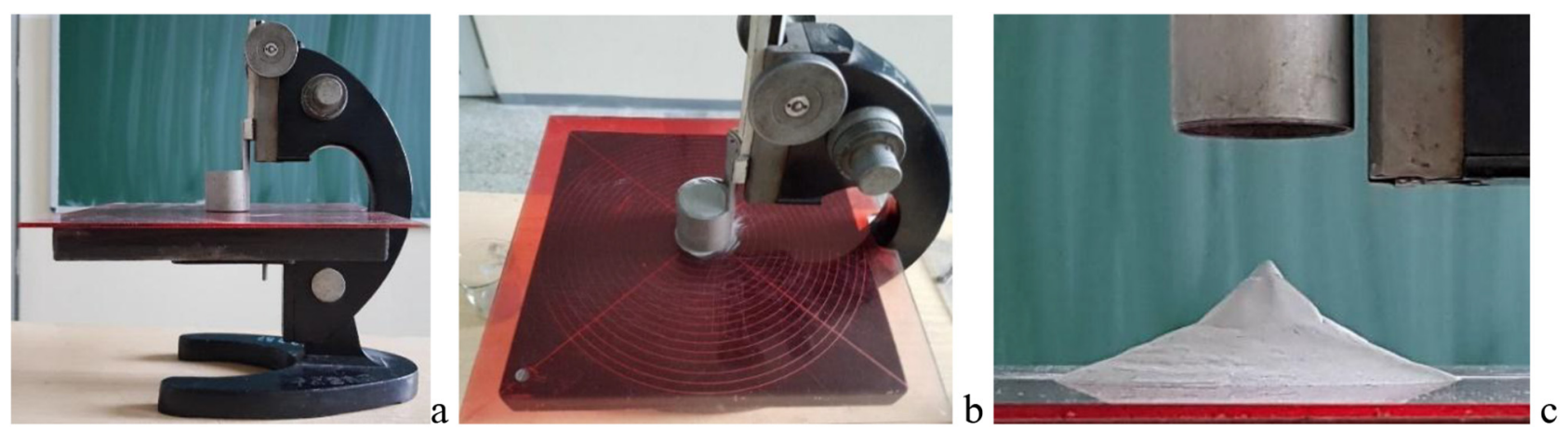

Fig. 3. Method used for AOR measurements: (a) device used for AOR measurements; (b) IN 625 powder placed in the device's holder (cylinder); (c) cone made by metallic powder after free flowing.

cylinder without a base connected to a rod that is placed on a flat surface. The cylinder that is placed on the flat surface is filled with powder and afterwards using the attached rod is lifted letting the powder to freely flow forming a cone. In order to determine the AOR, the diameter of the cone and its height are measured using a caliper and equation (7) is used for AOR calculation. Five measurements for each type of powder were made and the average values were calculated. Pictures of the powder cone were taken vertical to the cone section and processed in order to check the accuracy of the results obtained by caliper measuring (Fig. 3c).

$$
\tan \varphi=\frac{2 H}{D}
$$

where $\varphi$ is the AOR; $H$ is the height of the cone; $D$ is the diameter of the cone.

The values of the AOR that are under $30^{\circ}$ show that powders have a good flowability, while the values over $40^{\circ}$ suggest a bad flowability (cohesion between particles) [2]. The powder flow rate was measured using a Carney funnel and five samples of $150 \mathrm{~g}$ each.

\subsection{Results and discussions}

The results obtained from the sieving analysis showed the conformity of the PSD of both virgin and recirculated powders in accordance with the recommendations of the machine vendor. However, the analysis revealed that $100 \%$ of virgin powder has the grain size less than $50 \mu \mathrm{m}$ 
(no fractions were retained on the $50 \mu \mathrm{m}$ mesh sieve), while for recirculated powder samples, a small powder fraction $(0.6-0.7 \%)$ was retained on the $50 \mu \mathrm{m}$ mesh sieve. These particles could be originated from the laser-melt pool interaction when molten particles of different sizes may be spread on the powder bed. A slightly darker color of powders retained on the larger $45 \mu \mathrm{m}$ and $50 \mu \mathrm{m}$ mesh sieves was also observed.

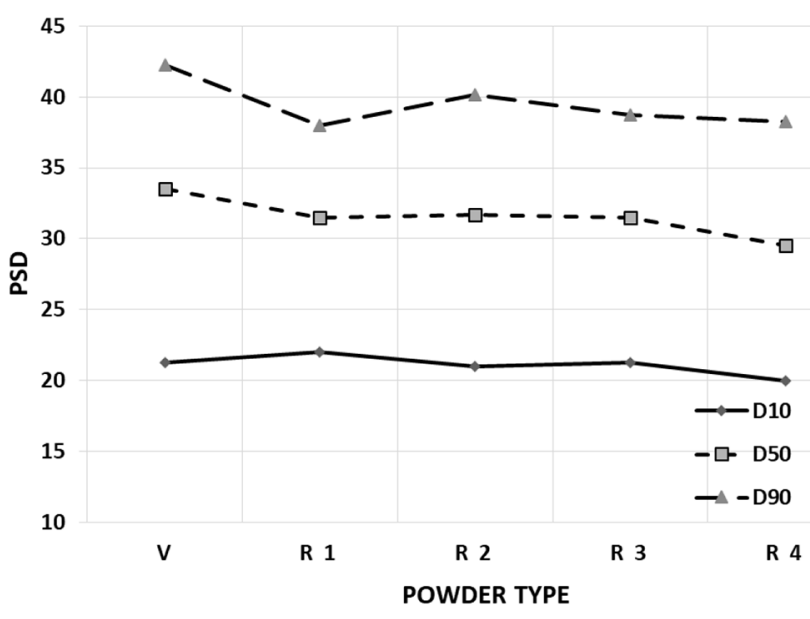

Fig. 4. PSD evolution.
A decrease in all D-values (D10, D50, D90) of the PSD was observed after multiple recirculation cycles showing a narrowing of the powder dimensional range (Fig. 4). The experimental results are in good agreement with the results obtained by different authors regarding other metallic powders used for AM [26-28]. After recycling, narrower distributions of the metal powder were reported as a result of powder layer spreading. During layer spreading some large particles can remain in the powder bed while other larger particles can be carried away or pushed toward sides by the machine wiper. Some authors findings [26,27] show that a narrower distribution after recycling ensures a higher flowability while other author show that larger particles ensure a higher flowing rate than smaller particles [29]. Smaller particles have the tendency to agglomerate and can have a negative influence on powder's flow capacity over time resulting in uneven distribution of powder layer or low random close packing (RCP) density. Pleass et al. [30] presented in their paper that a high RCP density can be obtained using a mixture of both large and small powder particles and that large proportions of particles with diameters smaller than $10 \mu \mathrm{m}$ can have a negative effect on the powder usability in an SLM process due to overwhelming cohesive forces.

Figures 5 and 6 present representative SEM images showing the morphology and surface quality of IN 625 powder. The virgin powder of IN 625 consists of mainly spheroidal particles under $45 \mu \mathrm{m}$ with smooth surface, however satellites particles were observed (Fig. 5c).
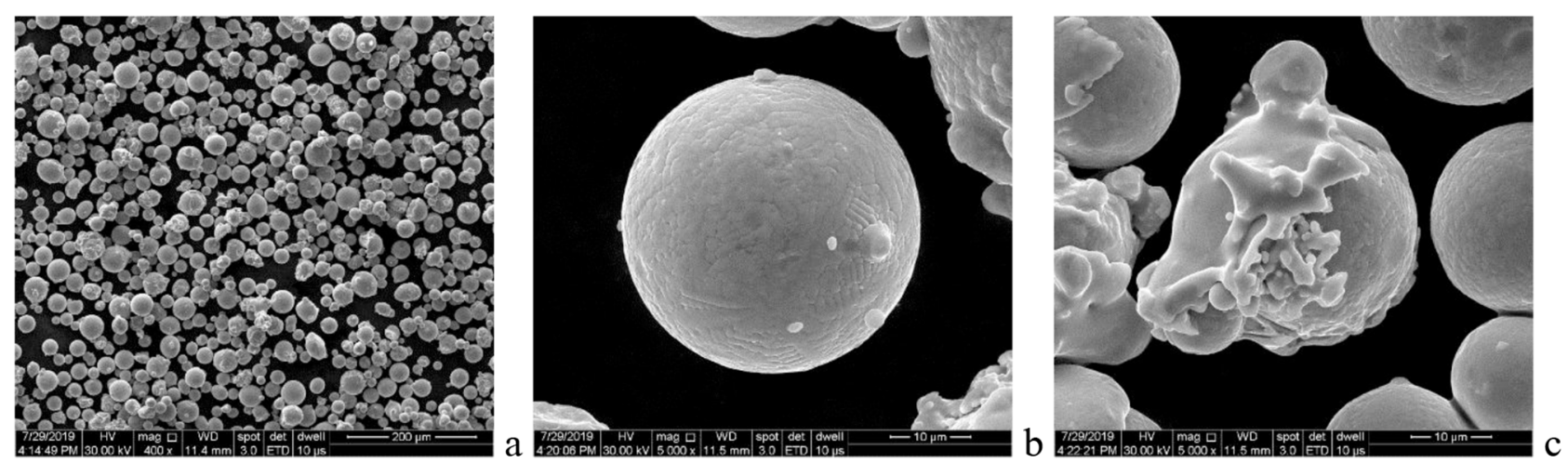

Fig. 5. SEM images with virgin powder of IN 625. Mostly spherical particles (a, b) with some particles with satellites (c).
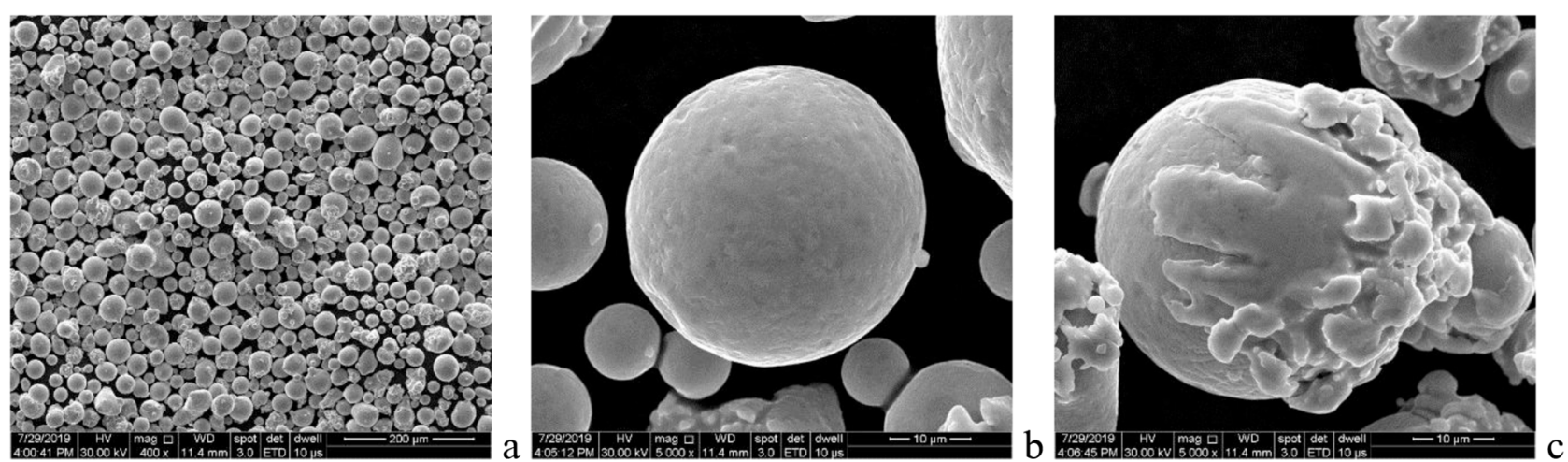

Fig. 6. SEM images with recirculated powder of IN 625. Mostly spherical particles (a, b) with some particles with satellites (c). 


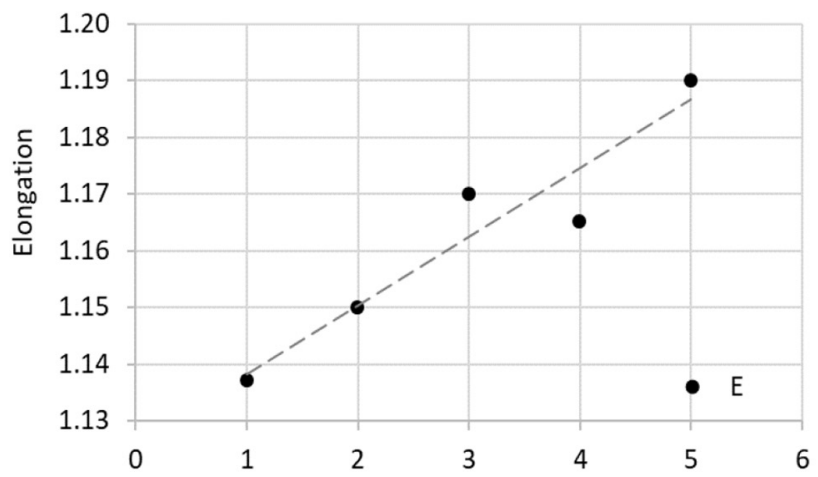

(a)

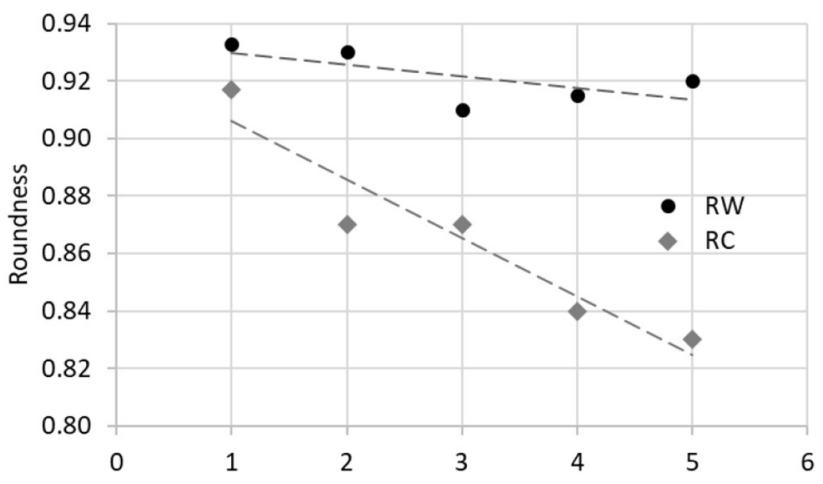

(b)

Fig. 7. Evolution of elongation (a) and roundness (b) of the IN 625 powder particles over multiple recirculation cycles.

Table 2. Apparent and tapped density of the IN 625 virgin and recirculated powders.

\begin{tabular}{|c|c|c|c|c|c|c|c|}
\hline Powder type & Density & 1 & 2 & 3 & Average & $\mathrm{HR}$ & $\mathrm{C}$ \\
\hline \multirow[t]{2}{*}{ V } & Apparent & 4.385 & 4.376 & 4.398 & 4.386 & 1.136 & 12.00 \\
\hline & Tapped & 4.983 & 4.973 & 4.998 & 4.985 & & \\
\hline \multirow[t]{2}{*}{$\mathrm{R} 1$} & Apparent & 4.39 & 4.385 & 4.387 & 4.387 & 1.138 & 12.08 \\
\hline & Tapped & 5 & 4.99 & 4.98 & 4.990 & & \\
\hline \multirow[t]{2}{*}{$\mathrm{R} 2$} & Apparent & 4.598 & 4.618 & 4.577 & 4.598 & 1.143 & 12.54 \\
\hline & Tapped & 5.273 & 5.272 & 5.225 & 5.257 & & \\
\hline \multirow[t]{2}{*}{ R3 } & Apparent & 4.6 & 4.62 & 4.59 & 4.603 & 1.145 & 12.57 \\
\hline & Tapped & 5.28 & 5.27 & 5.29 & 5.280 & & \\
\hline \multirow[t]{2}{*}{$\mathrm{R} 4$} & Apparent & 4.610 & 4.594 & 4.583 & 4.596 & 1.144 & 12.57 \\
\hline & Tapped & 5.239 & 5.227 & 5.304 & 5.257 & & \\
\hline
\end{tabular}

Smaller particles were joined with larger particles during the gas atomization process. Similar characteristics were observed for the recirculated powder, but in this case the particles are under $50 \mu \mathrm{m}$ in size. Satellite particles were observed as well, but in this case, they could be a result of liquid alloy sputtering during the AM process.

The results of elongation and roundness of the particles measurements are presented in Figure 7. The dimensional evolution analysis showed that particles are more elongated after multiple recirculation cycles. A deviation from the powder ideal roundness was also observed. Over multiple recirculation cycles the deviation is more pronounced.

Table 2 presents the obtained values for the apparent and tapped density of the IN 625 virgin and recirculated powders. Based on the powder apparent and tapped density the Hausner ratio and Carr index were determined, as presented in Figure 8.

An increase of both Hausner ratio and Carr index was noticed after multiple recirculation cycles. Still, the results indicate a good flowability and compressibility of the virgin and recirculated powders. As it was found, a Hausner ratio under 1.25 indicates that powders are less cohesive [2], and the Carr index is under a 16 value indicating a good compressibility which could ensure a good packing ability of the powder bed.
The flow rate was evaluated using the Carney funnel and no significant changes were observed between the virgin and recirculated powder flow rate, both exhibiting around $8 \mathrm{~s} / 150 \mathrm{~g}$, value within the data sheet specification $(<10 \mathrm{~s} / 150 \mathrm{~g})$.

The AOR determined using equation (7) was $28^{\circ}$ for virgin powder and $30^{\circ}$ for recirculated powder. It was experimentally proved that both virgin and recirculated powders produce two cones during free flow (a base cone and a top cone), as it is shown in Figure 9a. Thereby, three measurements were made on the pictures: measurements for the entire cone (Fig. 9b) and measurements for the two cones formed by the powder (Fig. 9c and d). The results of the top and base cones measurement showed that both cones present acute angles (the top cone presenting a larger angle than the base cone) and an AOR average value was determined based on the average results obtained in case of the AOR of the two cone types, for both virgin and recycled powder. These values were compared with the AOR determined by entire cone angle measured on images. No significant differences were observed by image measuring of the two powder cone types or the entire powder cone measurement (the difference between the average obtained in case of two cone types measurements and those of entire cone measurements was only $1^{\circ}$, for both virgin and 

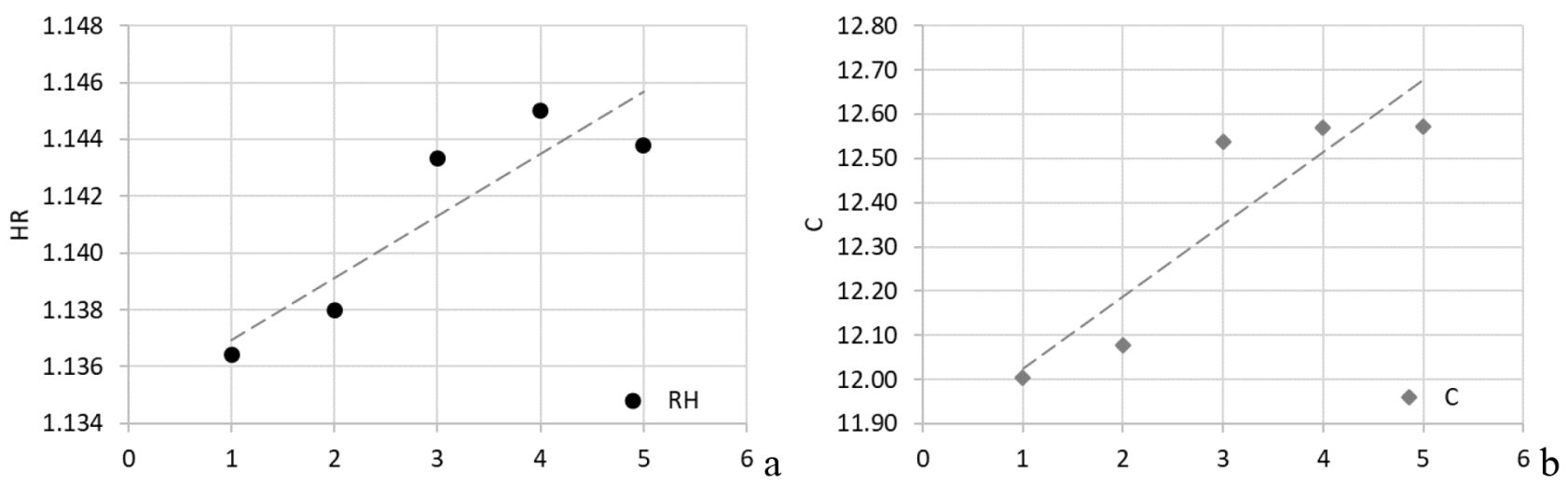

Fig. 8. Hausner ratio (a) and Carr index (b) evolution over multiple recirculation cycles.
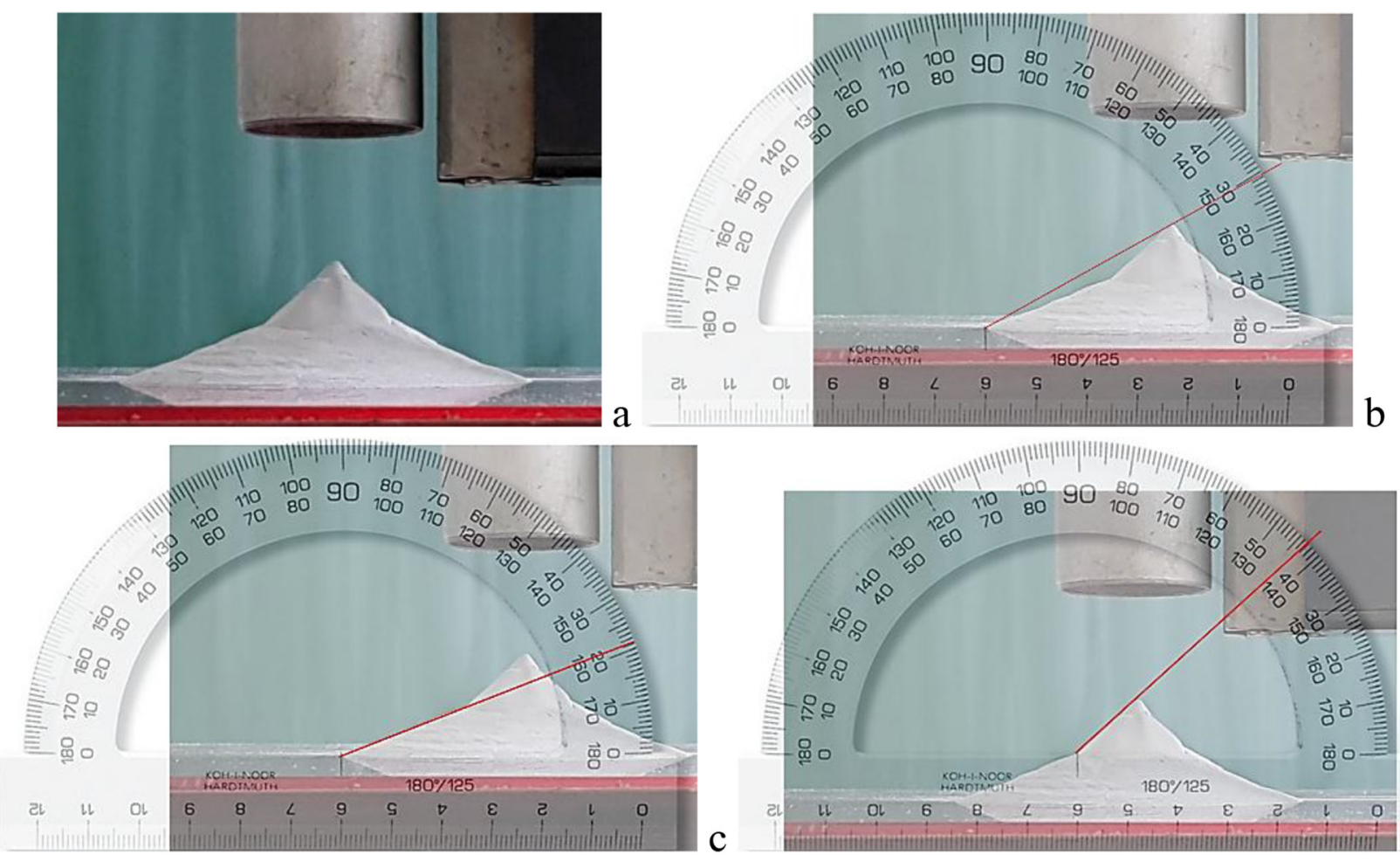

Fig. 9. AOR measurement based on image processing: a) initial picture; b) measurement of AOR for the entire cone; c) measurement of the AOR for the base cone; d) measurement of the AOR for the top cone.

recycled powders). However, differences were observed based on the AOR determined by caliper measurement on the actual powder cone and using equation (7) and AOR values determined by image processing. The average AOR determined based on image processing was $32^{\circ}$ for virgin powder and $33^{\circ}$ for recirculated powders, while the AOR determined using equation (7) were with $3^{\circ}-4^{\circ}$ lower. A slight increase of the AOR was observed after multiple recirculation cycles. Even if this increase was observed, the AOR is still under $40^{\circ}$ which shows a good powder flowability [3].

Currently, there is no standardized method for powder AOR measurement and different devices and methods are used by researchers. Based on the experimental procedure applied and the results obtained during the present work it can be proposed that both manual caliper measurements along with image processing measurements can be used in order to have a more accurate perspective on the powder characteristics evolution.

\section{Conclusions}

This study was carried out in order to determine the influence of recycling on the characteristics of IN 625 powder used for SLM process. As the Lasertec 30 SLM equipment has an imbedded recirculation system, and virgin powder was added over a period of 6 months, it has approximated that the powder was recirculated eight times 
(during 37 jobs). Physical and technological characteristics of virgin and recirculated powders were investigated. The study revealed:

- the powder size distribution analysis showed a decrease in all D-values $\left(\mathrm{D}_{10}, \mathrm{D}_{50}, \mathrm{D}_{90}\right)$ after multiple recirculation cycles proving a narrowing of the powder dimensional range which can have a negative effect on the flow capacity of the powder over time;

- both virgin and recirculated powders are composed of mainly spherical particles, satellites were observed in both cases as they were joined during the manufacturing of the powder or as a result of splashing during AM process;

- the dimensional evolution analysis showed that particles are more elongated after multiple recirculation cycles and an increase of the powder roundness deviation was observed after multiple recirculation cycles;

- based on Hausner ratio, flow rate evaluation and angle of repose measurements it was concluded that both virgin and recirculated powders present a good flowability. However, it can depreciate over multiple recirculating cycles.

Future studies should be conducted in order to determine the influence of powder recycling on material mechanical properties as well as an analysis to determine how many times the powder can be recirculated without affecting the characteristics of the powder bed and part properties.

The activity was carried out under "Nucleu" Program, Grant no. 2N/2019, Project PN 19.05.03.01, funded by Romanian Research and Innovation Ministry.

\section{References}

1. Q.B. Nguyen, M.L.S. Nai, Z. Zhu, C-N. Sun, J. Wei, W. Zhou, Engineering 3 (2017) 695-700

2. J.H. Tan, W.L.E. Wong, K.W. Dalgarno, Addit. Manuf. 18 (2017) 228-255

3. C. Meier, R. Weissbach, J. Weinberg, W.A. Wall, J. Mater. Process. Tech. 266 (2019) 484-501

4. I.E. Anderson, E.M.H. White, R. Dehoff, Curr. Opin. Solid State Mater. Sci. 22 (2018) 8-15

5. L. Markusson, Materials Engineering, Luea University of Technology, Master Thesis, 2017

6. Optimizing metal powders for additive manufacturing, Exploring the impact of particle morphology and powder flowability, Malvern Instruments Worldwide, 2017
7. R.M. German, Metall. Mater. Trans. A 23A (1992) $1455-1465$

8. M. Suzuki, Powder technology, fundamentals of particles, powder beds, and particle generation, in H. Masuda, K. Higashitani, H. Yoshida (Eds.) CRC Press, Boca Raton, 2007, pp. 293-308

9. A.B. Spierings, N. Herres, G. Levy, Proc. Solid Free. Fabr. Symp., 2010

10. R. Samant, Metal Powder Recycling and Reconditioning in Additive Manufacturing, EWI (2017)

11. P.D. Nezhadfar, A. Soltani-Tehrani, A. Sterling, N. Tsolas, N. Shamsaei, Proceedings of the 29th Annual International Solid Freeform Fabrication, 2018

12. E. Jelis, M. Clemente, S. Kerwien, N.M. Ravindra, M.R. Hespos, JOM 67 (2015) 582-589

13. G. Jacob, C. Brown, A. Donmez, S. Watson, J. Slotwinski, Adv. Manuf. Ser. 100 (2017) 6

14. L.C. Ardila, F. Garciandia, J.B. González-Díaz, P. Álvarez, A. Echeverria, M.M. Petite, R. Deffley, J. Ochoa, Phys. Procedia 56 (2014) 99-107

15. H.P. Tang, M. Qian, N. Liu, X.Z. Zhang, G.Y. Yang, J. Wang, JOM 67 (2015) 555-563

16. ISO 3310-1: Test sieves - Technical requirements and testing - Part1: Test sieves of metal wire cloth

17. DIN 66165-1: Particle size analysis - sieving analysis - Part 1: Fundamentals

18. DIN 66165-2: Particle size analysis - sieving analysis - Part 2: Procedure

19. ASTM B214-16: Standard Test Method for Sieve Analysis of Metal Powders

20. ISO/ASTM DIS 52907 Additive manufacturing - Feedstock materials - Methods to characterize metal powders

21. A. Cooke, J. Slotwinski, National Institute of Standards and Technology (2012)

22. ISO 3923-1: Metallic powders - Determination of apparent density - Part 1: Funnel method

23. ISO 3953: Metallic powders - Determination of tap density

24. ASTM B964: Standard Test Methods for Flow Rate of Metal Powders Using the Carney Funnel

25. Angle of Repose Testing for Metal Powders, LPW Brochure for Angle of Repose Testing

26. P.E. Carrion, A. Soltani-Tehrani, N. Phan, N. Shamsaei, JOM 71 (2019) 963-973

27. H.P. Tang, M. Qian, N. Liu, X.Z. Zhang, G.Y. Yang, J. Wang, JOM 67 (2015) 555-563

28. J.A. Slotwinski, E.J. Garboczi, P.E. Stutzman, C.F. Ferraris, S.S. Watson, M.A. Peltz, J. Res. Natl. Inst. Stand. Technol. 119 (2014) 460-493

29. J. Dawes, R. Bowerman, R. Trepleton, Johns. Matthey Technol. Rev. 59 (2015) 243-256

30. C. Pleass, S. Jothi, Addit. Manuf. 24 (2018) 419-431

Cite this article as: Mihaela Raluca Condruz, Gheorghe Matache, Alexandru Paraschiv, Characterization of IN 625 recycled metal powder used for selective laser melting, Manufacturing Rev. 7, 5 (2020) 